\title{
Microencapsulation of Paraffin with Poly (Urea Methacrylate) Shell for Solar Water Heater
}

\author{
Weiguang Su ${ }^{1, *(\mathbb{D}}$, Yilin Li ${ }^{2}$, Tongyu Zhou ${ }^{3} \mathbb{D}$, Jo Darkwa ${ }^{4}$, Georgios Kokogiannakis ${ }^{5}$ and \\ Zhao $\mathrm{Li}^{2}$ \\ 1 School of Mechanical \& Automotive Engineering, Qilu University of Technology (Shandong Academy \\ of Sciences), Jinan 250353, China \\ 2 School of Environment and Architecture, University of Shanghai for Science and Technology, \\ Shanghai 200093, China \\ 3 Department of Architecture and Built Environment, University of Nottingham Ningbo China, \\ Ningbo 315100, China \\ 4 Faculty of Engineering, University of Nottingham, Room B20 Lenton Firs, University Park, \\ Nottingham NG7 2RD, UK \\ 5 Sustainable Buildings Research Centre, University of Wollongong, Building 237, Squires Way, \\ Fairy Meadow NSW 2519, Australia \\ * Correspondence: weiguang.su@qlu.edu.cn or wgsuper@hotmail.com
}

Received: 9 August 2019; Accepted: 2 September 2019; Published: 4 September 2019

\begin{abstract}
Previous research has demonstred that microencapsulated phase change materials (MEPCMs) could significantly increase the energy storage density of solar thermal energy storage (TES) systems. Compared with traditional phase change materials (PCMs), MEPCMs have many advantages since they can limit their exposure to the surrounding environment, enlarge the heat transfer area, and maintain the volume as the phase change occurs. In this study, a new MEPCM for solar TES systems is developed by encapsulation of paraffin wax with poly (urea formaldehyde) (PUF). The experimental results revealed that agglomeration of MEPCM particles occurred during the encapsulation process which affected the uniformity of the particle size distribution profile when sodium dodecyl sulfate was used as an emulsifier. The differential scanning calorimetric (DSC) analysis results showed that the melting temperatures were slightly increased by $0.14-0.72{ }^{\circ} \mathrm{C}$ after encapsulation. A thermogravimetric (TG) test showed that the sample weight decreased while the weight loss starting temperature was slightly increased after encapsulation. Overall, the sample UF-2, fabricated with the binary emulsifiers of Brij 35 and Brij 30 and 5\% nucleating agent, resulted in good particle dispersion and shell integrity, higher core material content and encapsulation efficiency, as well as improved thermal stability.
\end{abstract}

Keywords: solar energy; thermal energy storage; microencapsulation; phase change material; poly (urea formaldehyde)

\section{Introduction}

Solar thermal energy storage (TES) systems have low operating costs and have been increasingly integrated into hot water systems and space heating services in buildings [1,2]. Meanwhile, solar energy is a leading source among alternative energy sources due to the advancement of solar technologies and its declining cost [3,4]. Solar systems are also leading to reductions of greenhouse gas emissions with a typical solar water heater being able to reduce about 2.5 tons of $\mathrm{CO}_{2}$ emissions per year [5]. However, current solar TES systems which use water as the heat storage medium tend to be relatively bulky. Past studies have shown that this physical limitation could be overcome by enhancing the energy storage density of the heat transfer fluid in the TES systems with solid-liquid phase change 
materials (PCMs) [5-7]. However, the current TES systems with solid-liquid PCMs often suffer from PCM leakage problems, which adds difficulties in applying PCMs into melting/freezing cycles [8], and their thermal energy charge/discharge rate is limited by their low thermal conductivity [9]. In order to overcome these issues, previous researchers have investigated several methods, such as incorporation of PCMs into polymer materials [10], embedding PCMs into high thermal conductivity supporting materials (i.e., graphene oxide matrix [11], expanded graphite [12], graphene nanoplatelets [9], and carbon nanotubes [13]) as form-stable PCMs, and microencapsulation of PCMs [14-16]. For instance, we have conducted a theoretical study and demonstrated that using microencapsulated phase change materials (MEPCMs) in a fixed bed TES system could store more thermal energy for a relatively smaller size of water tank compared with a traditional one [2]. Meanwhile, microencapsulation is an appealing option for integrating PCMs into TES systems since it could limit the exposure of PCMs to the surrounding environment, enlarge the heat transfer area of PCMs, and sustain the volume as the phase change occurs [17]. Therefore, this study focused on the development of a MEPCM with a suitable phase change temperature for TES systems.

In a previous review by Su et al., it was shown that in situ polymerization is a commonly used method for MEPCM production [17]. At the same time, poly (urea formaldehyde) (PUF) is a widely used shell material for fabrication of MEPCMs due to its high density, relatively high thermal conductivity, and ability to easily generate a crosslinking reaction resulting in good mechanical strength [17]. PUF is also able to be crosslinked at various formaldehyde/urea $(\mathrm{F} / \mathrm{U})$ molecular ratios. For instance, Tseng et al. [18] and Jin et al. [19] encapsulated paraffin waxes as MEPCM with a PUF shell at the F/U molar ratio of 1.5:1. Li et al. [20] and Xin et al. [21] fabricated the PUF shell at the F/U molar ratio of around 2:1. Zhang et al. [22] and Fang et al. [23] were also able to enlarge the F/U ratio to 3.34:1 and $3.45: 1$, respectively, for the fabrication of PUF shells. The FTIR examination results demonstrated good crosslinking reaction of PUF during the MEPCM fabrication at the F/U ratio of 3.34:1 [22] and 1.5:1 [19]. Moreover, adding the ammonium chloride as nucleating agent during the crosslinking process could provide hydrogen ions to the reaction system and ensure a smooth curing reaction [21].

Meanwhile, the selection of emulsifier is crucial for producing good quality MEPCMs in terms of morphology and shell integrity. For instance, sodium dodecyl sulfate (SDS) was introduced as an emulsifier to encapsulate n-tetradecane [23], n-pentadecane and n-eicosane [18], and n-hexadecane [20]. In all of these cases, as the amount of the SDS emulsifiers increased, the enthalpy of the fabricated MPECMs was also increased by $1.7-6.7 \%$ based on the weight of the core material. Jin et al. [19] prepared a MEPCM sample with styrene-maleic anhydride (SMA) as the emulsifier and paraffin as the core material. As a result, the average diameter of the capsules decreased and the MEPCM particle size distribution became narrower with increasing amounts of emulsifier. Xin et al. [21] combined poly (styrene-co-maleic anhydride) (SMA) and poly (oxyethylene octylphenol ether) (OP-10) at the ratio of 80:20 as binary emulsifiers to develop the MEPCM. The authors developed the MEPCM at the optimum crosslinking temperature of $65^{\circ} \mathrm{C}$, and the MEPCM had a core content of $52.8 \%$ and a thermal stability temperature of $220^{\circ} \mathrm{C}$. Konuklu et al. [24] combined two emulsifiers (Tween 40 and Tween 80) and microencapsulated a fatty acid with different shells. The results showed that the MEPCM prepared with PUF had higher latent heat and regular morphology, but lower thermal resistant temperatures compared with the capsules prepared with the shells of poly (melamine-formaldehyde) and poly (melamine-urea-formaldehyde). Su et al. [2] also developed MEPCM samples with two emulsifiers (Brij-30 and Brij-58) and compared the samples with a single emulsifier of SDS. The scanning electron microscopic (SEM) examination showed that the MEPCM fabricated with the binary emulsifiers achieved better morphologies than the one with SDS emulsifiers, although the SDS had hitherto been one of the most common emulsifiers for MEPCM fabrication.

The above highlighted investigations indicate some of the key factors that could affect the development of good MEPCMs. To this end, this study focused on the development and characterization of MEPCM samples with PUF shell, and also on the investigation of the effects of experimental parameters (i.e., emulsifier type (SDS and binary emulsifiers), optimized F/U ratios (3.34:1 and 1.5:1) 
and the dosage of nucleating agent) for the fabrication of MEPCMs. The raw materials and preparation method for MEPCM samples are described in Section 2. The properties of PCM (core material) and the developed MEPCM samples were then investigated with SEM, laser particle size analyzer, DSC, and thermogravimetric (TG) analysis, respectively.

\section{Materials and Methods}

\subsection{Raw Materials}

Table 1 presents the raw materials for the two MEPCM samples that were prepared in this study. A commercially available paraffin wax was chosen as the core material for MEPCM fabrication due to its relatively high latent heat capacity and suitable melting temperature at $48^{\circ} \mathrm{C}$ [25]. The melting temperature was identifiedby the fact that the outlet temperature of the fluid from a typical solar collector ranges between 40 and $60^{\circ} \mathrm{C}$ [26] (Table 1). The initial core/shell ratio was kept at 7:3 in order to maintain a reasonable balance between the thermal energy storage capacity and the mechanical strength of microcapsules. The Sinopharm Chemical Reagent Company supplied PUF shells crosslinked by urea (99\% purity) and $37 \mathrm{wt} \%$ formaldehyde solution. The emulsifier of SDS with a purity of $90 \%$ was supplied by Sinopharm Chemical Reagent Co., Ltd., China, while the binary emulsifiers Brij 35 and Brij 30 composed at weight ratio of 1:2 were obtained from Alfa Chemistry, USA, and Aladdin Industrial Corporation, Japan, respectively. The solutions of sodium hydroxide (Sinopharm Chemical Reagent Co., Ltd.) and citric acid (Sinopharm Chemical Reagent Co., Ltd.) were used to control pH values during the experimental process. Ammonium chloride $\left(\mathrm{NH}_{4} \mathrm{Cl}\right.$, Sinopharm Chemical Reagent Co., Ltd., purity $99.5 \%$ ) was used as a nucleating agent.

Table 1. Raw materials for microencapsulated phase change material (MEPCM) fabrication.

\begin{tabular}{ccccccc}
\hline Sample & Urea (g) & $\begin{array}{c}\text { Formaldehyde } \\
\mathbf{3 7} \mathbf{w t} \mathbf{0}(\mathbf{g})\end{array}$ & Emulsifier (s) & $\begin{array}{c}\text { Emulsifiers } \\
\mathbf{( g )}\end{array}$ & $\begin{array}{c}\text { Nucleating } \\
\text { Agent } \mathbf{( g )}\end{array}$ & $\begin{array}{c}\text { Paraffin } \\
\mathbf{( g )}\end{array}$ \\
\hline UF-1 & 1.54 & 6.95 & SDS & 0.25 & 0.36 & 8.40 \\
UF-2 & 2.48 & 5.03 & $\begin{array}{c}\text { Brij 35 \& Brij 30 } \\
\text { (weight ratio at 1:2) }\end{array}$ & 0.25 & 0.18 & 8.40 \\
\hline
\end{tabular}

\subsection{Fabrication Process of the MEPCM}

The detailed process for fabricating the MEPCM is demonstrated in Figure 1. By using the in situ polymerization method, the procedure for fabricating the MEPCM included synthesis of PUF prepolymer solution, oil-in-water $(\mathrm{O} / \mathrm{W})$ emulsion preparation, and formation of a PUF shell. Initially, a certain amount of urea (as shown in Table 1) was dissolved into $10 \mathrm{~mL}$ deionized water and stirred with a $37 \%$ formaldehyde solution at $200 \mathrm{rpm}$. The $\mathrm{pH}$ value of the mixture was then adjusted to $8.5-9$ by using a sodium hydroxide solution. The PUF prepolymer was prepared by heating the above mixture to $70{ }^{\circ} \mathrm{C}$ and then maintained for $30 \mathrm{~min}$ at a stirring speed of $200 \mathrm{rpm}$. By mixing the melted paraffin with the specified amount of emulsifier(s) and deionized water (as in Table 1), the O/W emulsion was prepared. The mixture was then kept at $80^{\circ} \mathrm{C}$ and it was stirred for $10 \mathrm{~min}$ at $7000 \mathrm{rpm}$ with an IKA T18 dispersion machine. In the next stage, the prepolymer solution was added into the $\mathrm{O} / \mathrm{W}$ emulsion to fabricate MEPCM capsules. The PUF shell crosslinked on the surface of oil particles had a lower $\mathrm{pH}$ value in the range of approximately $2-3$. This low $\mathrm{pH}$ level was achieved by adding a citric acid solution which helped to initiate the in situ polymerization process before adding the nucleating agent. The reaction for PUF shell generation was carried out for $4 \mathrm{~h}$ while the stirring speed was $500 \mathrm{rpm}$ and the reaction temperature was $80^{\circ} \mathrm{C}$. The crosslinking process was completed by adding sodium hydroxide solution to adjust the $\mathrm{pH}$ value of the slurry to 9.0. Finally, the MEPCM capsules were collected, washed, and dried in an oven at $70^{\circ} \mathrm{C}$ for $20 \mathrm{~h}$. 


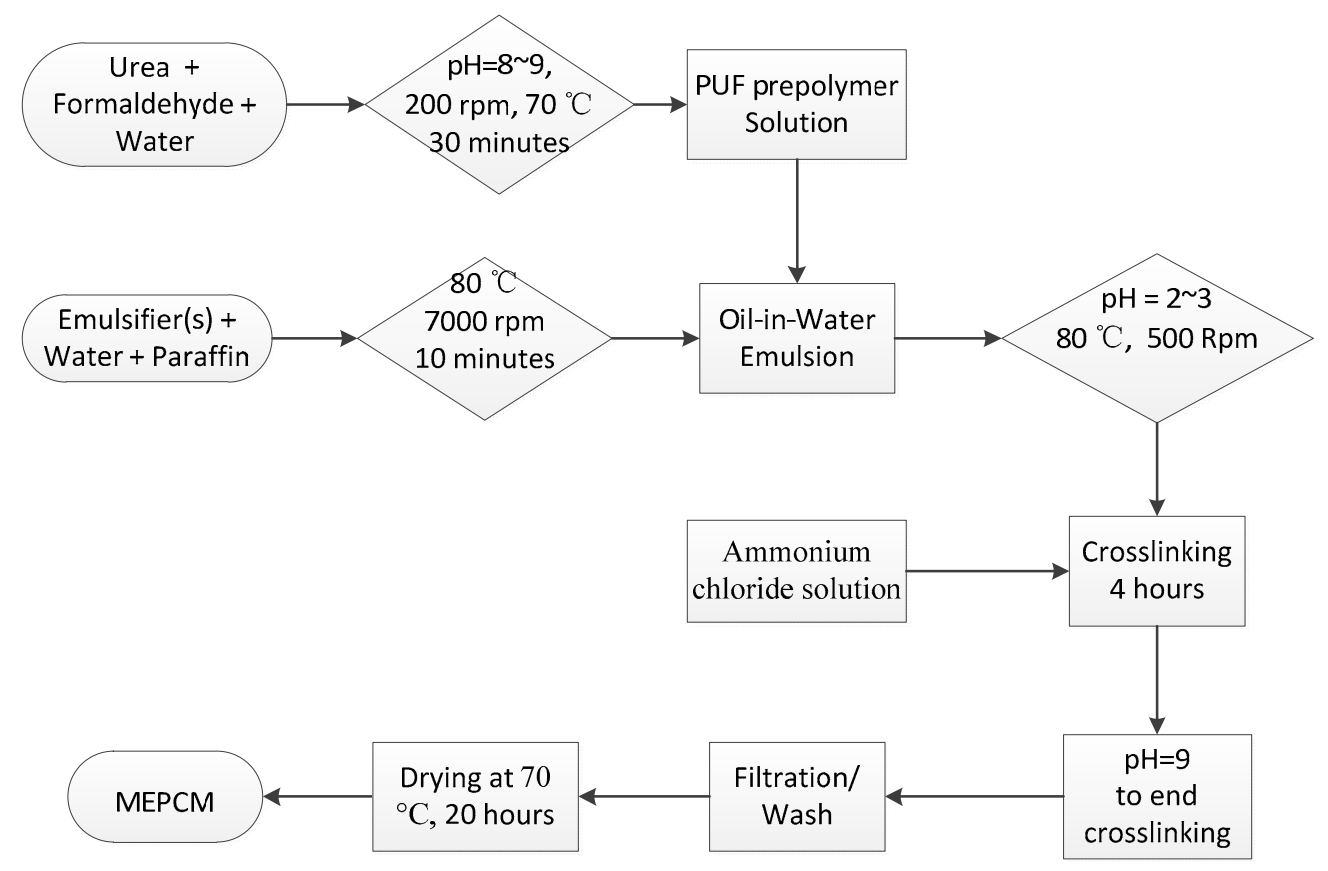

Figure 1. Microencapsulated phase change material (MEPCM) fabrication procedure.

\section{Results and Discussion}

\subsection{Morphology Analysis}

A Sigma VP SEM was used for the MEPCM capsules morphological analysis. In preparation for the SEM scanning, the MEPCM capsules were coated with $5 \mathrm{~nm}$ gold to enhance the conductivity of the samples [14]. As presented in Figure 2, the morphologies of the two samples from Table 1 were quite different. Figure 2a shows a serious particle agglomeration problem in the sample of UF-1, while the composite emulsifiers (Brij 35 and Brij 30) significantly improved the morphologies of capsules for UF-2 samples in Figure $2 \mathrm{~b}$. The differences in the morphologies of the two samples could have been caused by the different values of hydrophilic-lipophilic balance (HLB) values for the two type emulsifiers during MEPCM fabrication; for instance, the HLB value for SDS is 40 and the mixed emulsifiers (Brij $30+$ Brij 35) is 12. The serious agglomeration phenomenon in this experiment was similar to the one obtained by Fang [23], Tseng [18] and Li [20] when SDS was used as an emulsifier. In contrast, the morphology of the binary emulsifiers of nonionic mixed emulsifiers (Brij 35 and Brij 30) at a low HLB value was better than the morphology of SDS. This confirmed the findings from our previous research for the preparation of MEPCM with poly (melamine formaldehyde shell) [2].

The SEM images also demonstrate that, as a result of the agglomeration of capsules of UF-1, the particle sizes for sample UF-1 were much larger and the particle size distribution were broader than UF-2. More specifically, the diameters of UF-2 were in the range of 5-20 $\mu \mathrm{m}$ while most of the particle sizes of UF-1 were larger than $20 \mu \mathrm{m}$ and, in some cases, even larger than $100 \mu \mathrm{m}$ (Figure 2). 


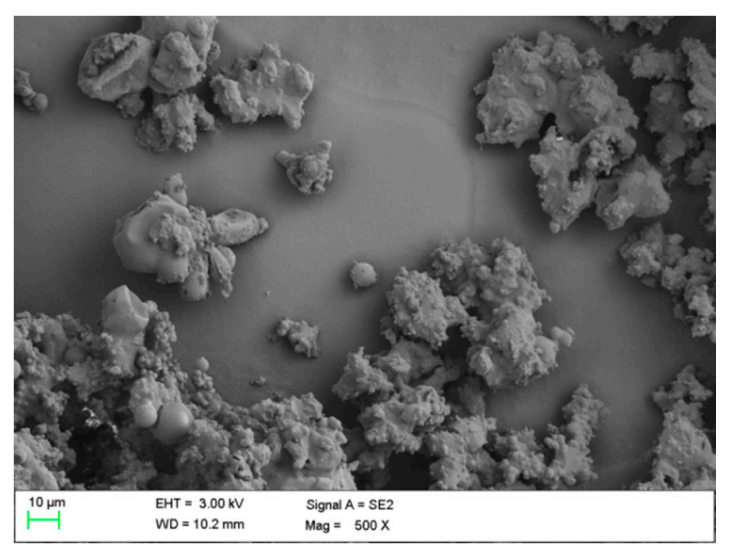

(a)

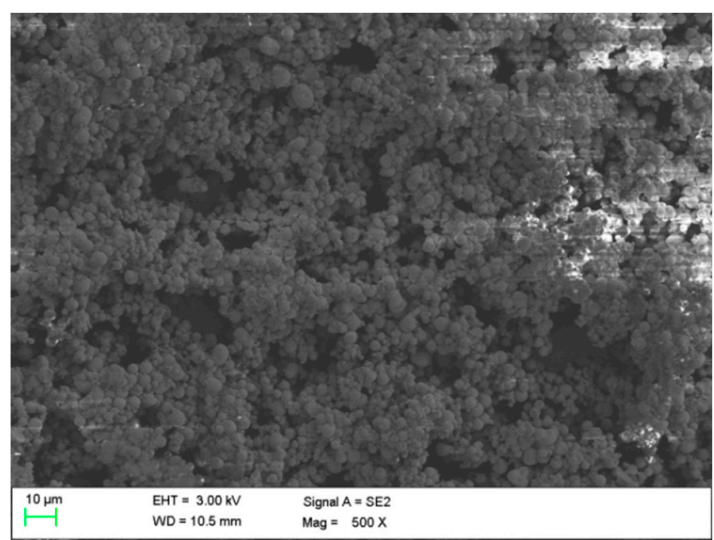

(b)

Figure 2. Scanning electron microscope (SEM) images of MEPCM samples. (a) UF-1; (b) UF-2.

\subsection{Particle Size Distribution}

Particle size distribution (PSD) was examined by Bettersize 2000 laser particle size analyzer in the same way as our previous study [14]. Figure 3 shows the particle size distribution of the fabricated MEPCM samples in a broad range of sizes up to over one hundred micrometers. The PSD profile of sample UF-1 in Figure 3a shows a wide range covering particle size of 20-200 $\mu \mathrm{m}$ with a large amount of capsules with diameters over $100 \mu \mathrm{m}$ due to particle agglomeration. On the other hand, sample UF-2 which was manufactured with the binary emulsifiers and contained less nucleating agent, displayed a narrower particle distribution profile (as shown in Figure 3b), with a large quantity of the particle diameters being measured in the range of 10-20 $\mu \mathrm{m}$. The PSD results were also consistent the SEM images shown in Figure 2. The above results revealed that the particle size distribution of MEPCM capsules can be greatly influenced by the dosage of ammonium chloride and the emulsifier types and thus, it should be carefully considered and optimized.

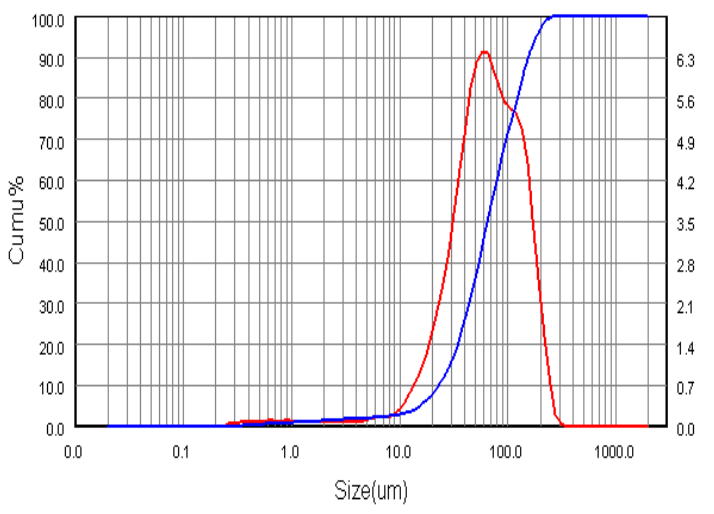

(a)

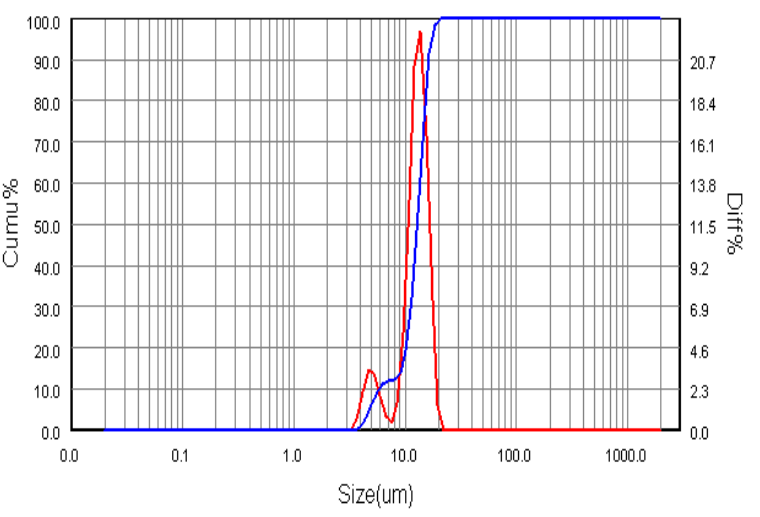

(b)

Figure 3. Particle size distribution (PSD) analysis of MEPCM samples. (a) UF-1; (b) UF-2.

\subsection{Energy Storage Capacity}

Based on the series of ISO 11357 Standards [27-29], the thermal energy storage capacities and melting temperature of paraffin and fabricated MEPCM samples were measured at atmospheric pressure and at a heating rate of $2{ }^{\circ} \mathrm{C} / \mathrm{min}$ from $5{ }^{\circ} \mathrm{C}$ to $65^{\circ} \mathrm{C}$ [2]. The latent heat capacities of pure paraffin, sample UF-1, and sample UF-2 are shown in Figure 4, and were found to be as much as 194.0, 124.7 , and $133.0 \mathrm{~kJ} / \mathrm{kg}$, respectively. The core material content for UF-1 (64.28\%) and UF-2 (68.55\%) was calculated based on the ratio of enthalpies of microcapsules to that of pure paraffin. As the initial ratio of core/shell weight was 7:3, the corresponding encapsulation efficiencies for UF-1 and UF-2 reached 
$91.82 \%$ and $97.93 \%$, respectively. The above results showed that higher core material content and encapsulation efficiency was obtained with $10 \mathrm{wt} \%$ and $5 \mathrm{wt} \%$ of nucleating agent in UF-1 and UF-2, respectively. Table 2 summarizes the results of latent heat, core material content and encapsulation efficiency of the paraffin and fabricated MEPCM samples. These results also indicate that the combined emulsifiers did improve the core material content and the encapsulation efficiency of UF-2 sample as compared with the UF-1 sample prepared with SDS. By conducting DSC measurements, the phase change of the core material (paraffin) was found to take place between 48.34 and $59^{\circ} \mathrm{C}$. Meanwhile, the melting temperatures of the two developed samples were slightly increased by $0.72{ }^{\circ} \mathrm{C}$ for UF- 1 and by $0.14{ }^{\circ} \mathrm{C}$ for UF-2 after encapsulation.

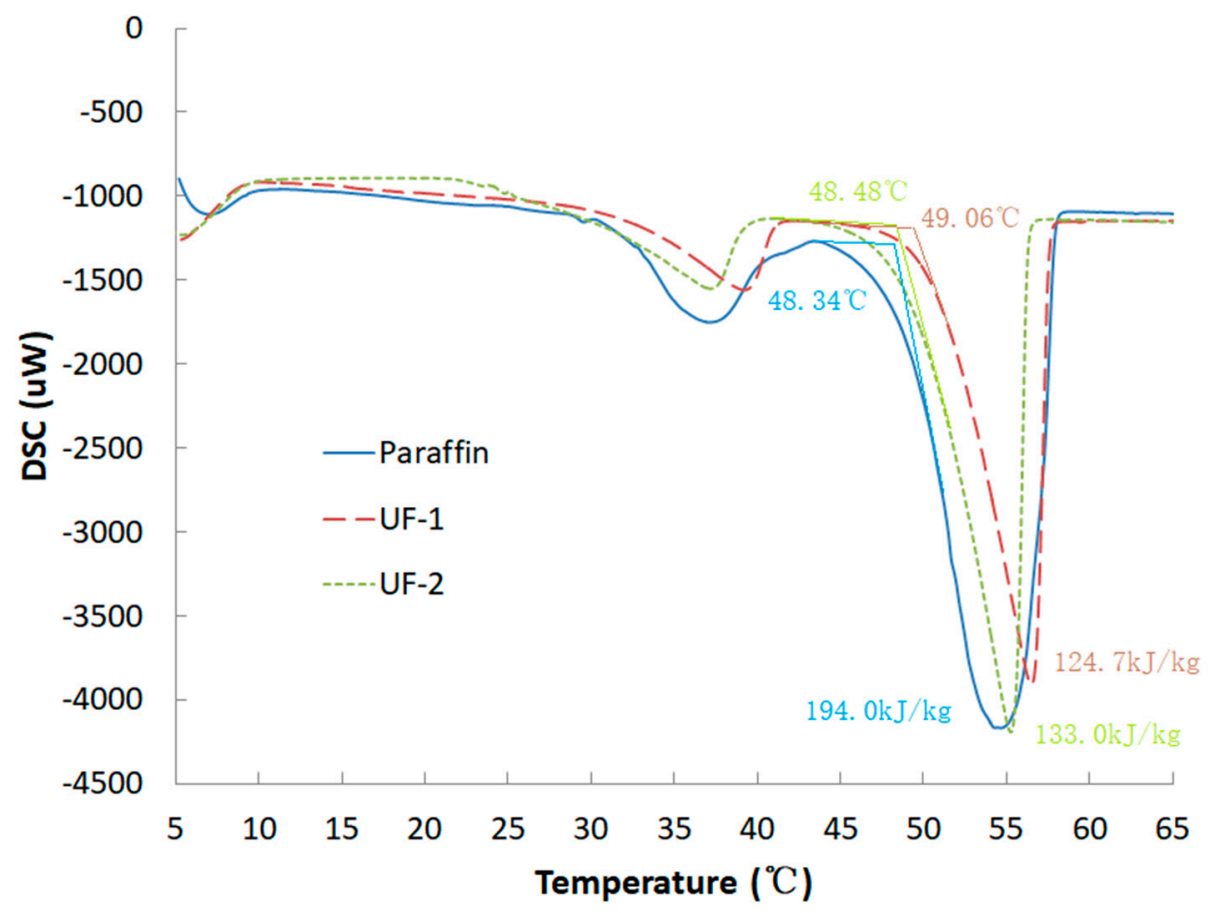

Figure 4. Differential scanning calorimetric (DSC) curves of paraffin and MEPCM samples.

Table 2. Thermophysical properties of core materials and fabricated MEPCM samples.

\begin{tabular}{cccccc}
\hline Item & $\begin{array}{c}\text { Melting } \\
\text { Point }\left({ }^{\circ} \mathbf{C}\right)\end{array}$ & $\begin{array}{c}\text { Latent Heat } \\
\mathbf{( k J / k g )}\end{array}$ & $\begin{array}{c}\text { Core Material } \\
\text { Content }(\mathbf{w t} \%)\end{array}$ & $\begin{array}{c}\text { Encapsulation } \\
\text { Efficiency }(\%)\end{array}$ & $\begin{array}{c}\text { Weight Loss Starting } \\
\text { Temperature }\left({ }^{\circ} \mathbf{C}\right)\end{array}$ \\
\hline Paraffin & 48.34 & 194.0 & - & - & 238.0 \\
UF-1 & 49.06 & 124.7 & 64.28 & 91.82 & 247.0 \\
UF-2 & 48.48 & 133.0 & 68.55 & 97.93 & 265.0 \\
\hline
\end{tabular}

\subsection{Thermal Stability}

The thermal stability of paraffin and MEPCM samples was evaluated through TG analysis by using EXSTAR6000 TG/DTA6300 (EXSTAR6000 TG/DTA6300, SII NanoTechnology Inc., Japan). The samples were tested under the protection of nitrogen gas by heating the test environment up to $500{ }^{\circ} \mathrm{C}$ with a rate of $10^{\circ} \mathrm{C} / \mathrm{min}$ [14]. The TG results in Figure 5 showed that the thermal stability of the samples did not significantly improve after encapsulation. Although the PUF shell could help the capsules remain in solid state during melting and solidification cycles after encapsulation, the weight loss start temperatures for UF-1 and UF-2 only increased by 9 and $27^{\circ} \mathrm{C}$, respectively. The reason for this small increase is that the melting temperature of PUF resin is only $200^{\circ} \mathrm{C}$, and the PUF shell deforms when the paraffin starts to evaporate at $238^{\circ} \mathrm{C}$. However, when comparing the thermophysical properties of the two MEPCM samples, the capsules (UF-2) manufactured with the mixed emulsifier demonstrated much better thermal stability than the capsules (UF-1) fabricated with SDS as demonstrated in Table 2 . 


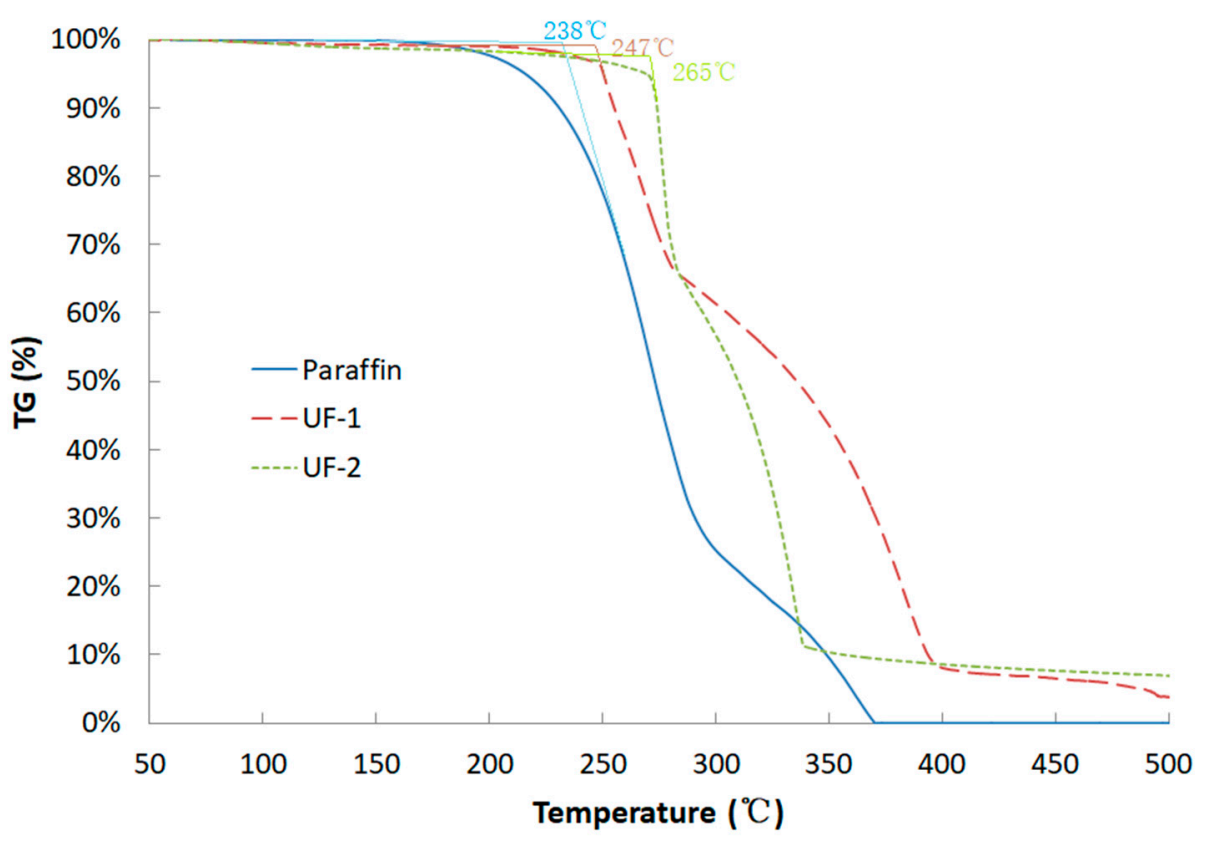

Figure 5. Thermogravimetric (TG) analysis of paraffin and developed MEPCMs.

\section{Conclusions}

The aim of this study was to develop an MEPCM with good thermophysical properties for solar TES systems. To this end, a paraffin with a melting temperature over $48{ }^{\circ} \mathrm{C}$ was selected as the core material. The experimental results showed that the MEPCM samples have been successfully fabricated by the in situ polymerization method within PUF resin shell. The emulsifiers proved to have a strong influence on the core material content and encapsulation efficiency according to SEM and DSC measurements. By using the binary emulsifiers of Brij 35 and Brij 30 and 5\% nucleating agent, an MEPCM (UF-2) with high melting temperature at relatively high encapsulation efficiency of $97.93 \%$ can be produced. The TG test results showed that the sample weight dropped while the weight loss starting temperature was slightly increased after encapsulation. The key outcomes of this research are summarized as follows:

(a) Agglomeration of MEPCM particles did occur during the encapsulation process which affected the uniformity of the PSD profile, especially for the sample with the emulsifier of SDS.

(b) Compared with the original paraffin, there was a slight increase of $0.14-0.72{ }^{\circ} \mathrm{C}$ in the melting temperature of the MEPCM samples.

(c) The dosage of $5 \mathrm{wt} \%$ nucleating agent (ammonium chloride) and the binary emulsifies (Brij 35 and Brij 30) resulted in higher core material content of $68.55 \%$ and encapsulation efficiency of 97.93\% for the developed MEPCM.

(d) The thermal stability was only slightly enhanced by $9-27^{\circ} \mathrm{C}$ after encapsulation due to the fact that PUF has a lower melting temperature than the evaporation temperature of the paraffin wax.

Overall, the fabricated MEPCM has the potential of improving the energy storage density of solar hot water TES in residential and commercial buildings. By integrating the fabricated MEPCM into solar systems for hot water and heating purposes, lower initial costs and smaller physical storage sizes could be achieved and, therefore, the development of future prototypes in this regard is a promising research topic.

Author Contributions: Conceptualization, W.S. and Y.L.; Methodology, W.S.; Formal analysis, W.S., Y.L. and T.Z.; Investigation, W.S.; Writing—original draft preparation, W.S.; Writing—review \& editing, Y.L., T.Z., J.D., G.K. and Z.L.; Funding acquisition, W.S. 
Funding: This research was funded by Natural Science Foundation of Shandong Province, grant number ZR2017LEE017; Doctoral Scientific Research Foundation of Qilu University of Technology, grant number 0412048475; and Youth Doctoral Cooperation Project of Qilu University of Technology (Shandong Academy of Science), grant number 2018BSHZ0023.

Acknowledgments: The authors wish to express their thanks to the very competent reviewers for the valuable comments and suggestions.

Conflicts of Interest: The authors declare no conflict of interest.

\section{References}

1. Belmonte, J.F.; Eguía, P.; Molina, A.E.; Almendros-Ibáñez, J.A.; Salgado, R. A simplified method for modeling the thermal performance of storage tanks containing PCMs. Appl. Therm. Eng. 2016, 95, 394-410. [CrossRef]

2. Su, W.; Darkwa, J.; Kokogiannakis, G.; Zhou, T.; Li, Y. Preparation of microencapsulated phase change materials (MEPCM) for thermal energy storage. Energy Procedia 2017, 121, 95-101. [CrossRef]

3. Rashid, K.; Safdarnejad, S.M.; Ellingwood, K.; Powell, K.M. Techno-economic evaluation of different hybridization schemes for a solar thermal/gas power plant. Energy 2019, 181, 91-106. [CrossRef]

4. Ellingwood, K.; Safdarnejad, S.M.; Rashid, K.; Powell, K. Leveraging Energy Storage in a Solar-Tower and Combined Cycle Hybrid Power Plant. Energies 2018, 12, 40. [CrossRef]

5. Nazir, H.; Batool, M.; Osorio, F.J.B.; Isaza-Ruiz, M.; Xu, X.; Vignarooban, K.; Phelan, P.; Inamuddin; Kannan, A.M. Recent developments in phase change materials for energy storage applications: A review. Int. J. Heat Mass Transf. 2019, 129, 491-523. [CrossRef]

6. Khan, M.M.A.; Ibrahim, N.I.; Mahbubul, I.; Ali, H.M.; Saidur, R.; Al-Sulaiman, F.A. Evaluation of solar collector designs with integrated latent heat thermal energy storage: A review. Sol. Energy 2018, 166, 334-350. [CrossRef]

7. Li, T.; Xu, J.; Wu, D.; He, F.; Wang, R. High energy-density and power-density thermal storage prototype with hydrated salt for hot water and space heating. Appl. Energy 2019, 248, 406-414. [CrossRef]

8. Şahan, N.; Paksoy, H. Novel shapeable phase change material (PCM) composites for thermal energy storage (TES) applications. Sol. Energy Mater. Sol. Cells 2018, 174, 380-387. [CrossRef]

9. Ramakrishnan, S.; Wang, X.; Sanjayan, J. Thermal enhancement of paraffin/hydrophobic expanded perlite granular phase change composite using graphene nanoplatelets. Energy Build. 2018, 169, 206-215. [CrossRef]

10. Chalco-Sandoval, W.; Fabra, M.J.; Lopez-Rubio, A.; Lagarón, J.M.; Fabra, M.J. Development of polystyrene-based films with temperature buffering capacity for smart food packaging. J. Food Eng. 2015, 164, 55-62. [CrossRef]

11. Su, W.; Darkwa, J.; Li, Y.; Lv, Y. Novel method for fabricating high thermal conductivity form-stable Phase Change Materials. In Proceedings of the 17th International Conference on Sustainable Energy Technologies-SET 2018, Wuhan, China, 21-23 August 2018.

12. Lin, Y.; Zhu, C.; Alva, G.; Fang, G. Palmitic acid/polyvinyl butyral/expanded graphite composites as form-stable phase change materials for solar thermal energy storage. Appl. Energy 2018, 228, 1801-1809. [CrossRef]

13. Ramakrishnan, S.; Wang, X.; Sanjayan, J. Effects of various carbon additives on the thermal storage performance of form-stable PCM integrated cementitious composites. Appl. Therm. Eng. 2019, 148, 491-501. [CrossRef]

14. Su, W.; Darkwa, J.; Kokogiannakis, G. Nanosilicon dioxide hydrosol as surfactant for preparation of microencapsulated phase change materials for thermal energy storage in buildings. Int. J. Low Carbon Technol. 2018, 13, 301-310. [CrossRef]

15. Sari, A.; Alkan, C.; Bilgin, C. Micro/nano encapsulation of some paraffin eutectic mixtures with poly(methyl methacrylate) shell: Preparation, characterization and latent heat thermal energy storage properties. Appl. Energy 2014, 136, 217-227. [CrossRef]

16. Jiang, X.; Luo, R.; Peng, F.; Fang, Y.; Akiyama, T.; Wang, S. Synthesis, characterization and thermal properties of paraffin microcapsules modified with nano- $\mathrm{Al}_{2} \mathrm{O}_{3}$. Appl. Energy 2015, 137, 731-737. [CrossRef]

17. Su, W.; Darkwa, J.; Kokogiannakis, G. Review of solid-liquid phase change materials and their encapsulation technologies. Renew. Sustain. Energy Rev. 2015, 48, 373-391. [CrossRef] 
18. Tseng, Y.-H.; Fang, M.-H.; Tsai, P.-S.; Yang, Y.-M. Preparation of microencapsulated phase-change materials (MCPCMs) by means of interfacial polycondensation. J. Microencapsul. 2005, 22, 37-46. [CrossRef]

19. Jin, Z.; Wang, Y.; Liu, J.; Yang, Z. Synthesis and properties of paraffin capsules as phase change materials. Polymer 2008, 49, 2903-2910. [CrossRef]

20. Li, M.G.; Zhang, Y.; Xu, Y.H.; Zhang, D. Effect of different amounts of surfactant on characteristics of nanoencapsulated phase-change materials. Polym. Bull. 2011, 67, 541-552. [CrossRef]

21. Xin, C.; Tian, Y.; Wang, Y.; Huang, X. Effect of curing temperature on the performance of microencapsulated low melting point paraffin using urea-formaldehyde resin as shell. Text. Res. J. 2013, 84, 831-839. [CrossRef]

22. Zhang, X.; Tao, X.; Yick, K.; Wang, X. Structure and thermal stability of microencapsulated phase-change materials. Colloid Polym. Sci. 2004, 282, 330-336. [CrossRef]

23. Fang, G.; Li, H.; Yang, F.; Liu, X.; Wu, S. Preparation and characterization of nano-encapsulated n-tetradecane as phase change material for thermal energy storage. Chem. Eng. J. 2009, 153, 217-221. [CrossRef]

24. Konuklu, Y.; Paksoy, H.Ö.; Unal, M.; Konuklu, S. Microencapsulation of a fatty acid with Poly(melamineurea-formaldehyde). Energy Convers. Manag. 2014, 80, 382-390. [CrossRef]

25. Su, W.; Darkwa, J.; Kokogiannakis, G. Development of microencapsulated phase change material for solar thermal energy storage. Appl. Therm. Eng. 2017, 112, 1205-1212. [CrossRef]

26. Seddegh, S.; Wang, X.; Henderson, A.D.; Xing, Z. Solar domestic hot water systems using latent heat energy storage medium: A review. Renew. Sustain. Energy Rev. 2015, 49, 517-533. [CrossRef]

27. International Organization for Standardization (IOS). Plastics-Differential Scanning Calorimetry (DSC) Part 1: General Principles; International Organization for Standardization: Geneva, Switzerland, 2016.

28. International Organization for Standardization (IOS). Plastics-Differential Scanning Calorimetry (DSC) Part 3: Determination of Temperature and Enthalpy of Melting and Crystallization; International Organization for Standardization: Geneva, Switzerland, 2018.

29. International Organization for Standardization (IOS). Plastics-Differential Scanning Calorimetry (DSC) Part 5: Determination of Characteristic Reaction-curve Temperatures and Times, Enthalpy of Reaction and Degree of Conversion; International Organization for Standardization: Geneva, Switzerland, 2013.

(C) 2019 by the authors. Licensee MDPI, Basel, Switzerland. This article is an open access article distributed under the terms and conditions of the Creative Commons Attribution (CC BY) license (http://creativecommons.org/licenses/by/4.0/). 